\title{
DECIDEIX. PROGRAMA DE COMPETÈNCIA SOCIAL
}

\author{
M. Teresa Vallverdú March. Mestra del CEIP “Alberich i Cases”. Reus
}

A l'escola ens trobem, cada cop més sovint, amb problemes que no sabem com resoldre i necessitats que no podem atendre: agressivitat verbal $i$ fins $i$ tot física entre iguals; manca de respecte amb ells mateixos i vers les persones adultes, mestres, monitors/es...; desmotivació de cara a l'estudi i tota activitat que comporti un esforç, majorment si aquest és intel-lectual; dificultats d'aprenentatge a les àrees instrumentals bàsiques que ocasionen llacunes difícils d'omplir; absentisme, a vegades justificat per les famílies; poc respecte a les normes de convivència, que deriva en problemes de comportament i de relació i "s'arreglen" o pretenem "arreglar" amb reglaments de règim intern més estrictes en els càstigs...

Aquestes situacions no es donen perquè sí; tenen unes causes, les més freqüents de les quals serien:

- Impulsivitat. Davant de qualsevol estímul, per petit que sigui, de seguida se salta; un exemple és quan demanes alguna cosa a classe, i abans de dir què vols, ja n'hi ha quatre o cinc amb la mà aixecada.

- Manca d'autocontrol. No poden dominar les emocions, en especial les d'enuig, còlera o ràbia. Sempre sembla que tinguin tres anys i no paren de tenir enrabiades, com quan es té aquesta edat.

- Ansietat. Tot ha de ser al moment, no es poden esperar, contínuament necessiten nous al-licients per continuar i mai no se senten satisfets/es.

- Diàleg intern pobre. No es paren a pensar en el que fan ni s'ho qüestionen.

- Dificultats d'organització, segurament fruit de l'excessiu proteccionisme de les famílies, de donarlos-ho tot massa "mastegat" i de la poca capacitat de gestió del temps que tenen.

- Poca adaptació a situacions noves, en un moment en què es fa més palesa aquesta qualitat perquè tot canvia tan ràpidament.

- Manca de percepció social, i en conseqüència, molt d'egocentrisme: el món gira a l'entorn seu i són "els reis del mambo".

- Manca de percepció del risc, pròpia de l'edat, però en alguns casos exagerada per la influència dels films violents... i més perillosa pels molts mitjans de prendre mal que tenen a l'abast.

- Incapacitat per generar alternatives, ajudada pel pensament únic imperant: les coses només poden ser o blanques o negres.

- Poques habilitats per establir la relació causaefecte. Davant d'un problema els costa molt saberlo definir i mirar de saber per què el tenen...

El programa de competència social Decideix és un material publicat per la Conselleria d'Educació del Govern de les illes Canàries i cedit al Departament d'Ensenyament. Els autors són Manuel Segura Morales, Juana R. Expósito i Margarita Arcas Cuenca, i les il-lustracions, d’Arturo Nuez Ramos, Rubén Lima González i José Carlos Pérez Díaz.

El programa de competència social Decideix vol donar, i de fet, per la meva experiència, dóna resposta a aquesta demanda d'eines i materials a una edat en què pel fet de tenir la població en l'àmbit escolar es pot incidir força en la formació de la manera de ser. Serveix per fer front de manera col-lectiva al repte d'ajudar els nois i noies a ser persones assertives, a ser millors persones i a millorar les relacions entre tothom.

Decideix és un programa per a Primària amb dos volums, el primer per a Cicle Mitjà i el segon per a Cicle Superior, adreçat a la solució de problemes mitjançant el desenvolupament de les habilitats socials i cognitives.

La seva continuació a l'Educació Secundària Obligatòria, amb dos volums, un per a cada cicle, es diu: Programa de competència social: Habilitats cognitives. Valors morals. Habilitats socials.

L'experiència d'aplicació del programa durant diversos anys confirma els seus bons resultats en la prevenció de problemes socials, com a potenciador de les relacions humanes de l'alumnat.

L'avaluació del programa nord-americà Think Aloud de Camp i Basch (que s'ha tingut en compte a l'elaborar el programa Decideix) conclou que pràcticament en totes les variables els resultats obtinguts amb el programa van ser millors i més duradors que amb altres programes.

També se'n fa una valoració molt positiva en la tesi doctoral de M. Dolores Martínez Francés: La intervenció educativa per a la prevenció de la conducta antisocial a 


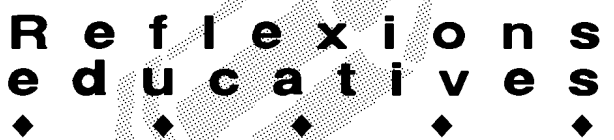

l'escola, i en la de Maria J. Suárez Rodríguez: Las habilidades sociales en niños sordos profundos.

Un concepte fonamental per entendre el suport teòric d'aquest programa és el de mediació verbal. S'anomena mediació verbal l'ús del llenguatge com un regulador intern del pensament racional i lògic. L'ús de la mediació verbal es desenvolupa, normalment, entre els cinc i els set anys d'edat, i passa de processar la informació associativament a fer-ho cognitivament (WHITE, 1970).

D'acord amb els treballs de Luria (1961) i Vygotsky (1962), que plantegen les etapes del desenvolupament de la funció inhibidora del llenguatge i dels estudis realitzats per B.W. Camp (1977), sorgeixen les següents conclusions: Un desenvolupament adequat de la mediació verbal facilita la internalització de la funció inhibidora del llenguatge, que serveix per bloquejar les reaccions impulsivo-associatives, tant en el camp cognitiu com en el camp social.

La mediació verbal serveix, igualment, per facilitar l'aprenentatge, la solució de problemes i la previsió de conseqüències.

A partir d'aquestes conclusions surten multitud de programes per desenvolupar correctament la mediació verbal. Aquest n'és un.

L' objectiu del programa és arribar que les persones siguem assertives i que tinguem competència social. Les persones, de natural, som agressives o inhibides en els nostres comportaments. També pot ser que en unes ocasions actuem de forma inhibida $i$ en altres agressiva. L'exemple al regne animal és que ens comportem com ratolins o com lleons. La competència social suposa el desenvolupament d'habilitats i destreses específiques que fan del subjecte un ésser capaç d'autoregular-se, de comprendre's a si mateix i de comprendre els altres. L'assertivitat és, doncs, la manera de dir i fer allò que nosaltres pensem sense fer mal als altres.

El programa es basa en:

1. El desenvolupament de la intel.ligència interpersonal, que és una de les set intel-ligències que descriu la teoria de Howard Gardner (1988 i 1995). És la capacitat de posar-se en el lloc de l'altre i saber-lo tractar. És la intel-ligència que han de tenir més desenvolupada els venedors, dirigents, i que caldria que tingués tothom. Per tal de millorar les habilitats cognitives, s'entrenen els cinc pensaments que Spivaack i Shure (1974) van demostrar que eren imprescindibles per a una bona relació interpersonal, i que són: causal, alternatiu, conseqüencial, perspectiva i mitjans-fi.

2. Raonament moral i valors. Es fa amb l'enfocament cognitiu i evolutiu dels sis estadis de Piaget $i$ Kohlberg. És un pas molt important aquesta concepció dels valors morals respecte a les idees anteriors. Els valors morals es construeixen. Es tracta d'ajudar que cadascú pugi com a mínim un estadi moral.

3. Habilitats socials, amb el mètode estructurat de Goldstein i control emocional de Goleman. Es van treballant al llarg de tot el programa, però a més a més donen pautes de com treballar les més importants: demanar un favor, saber donar les gràcies...

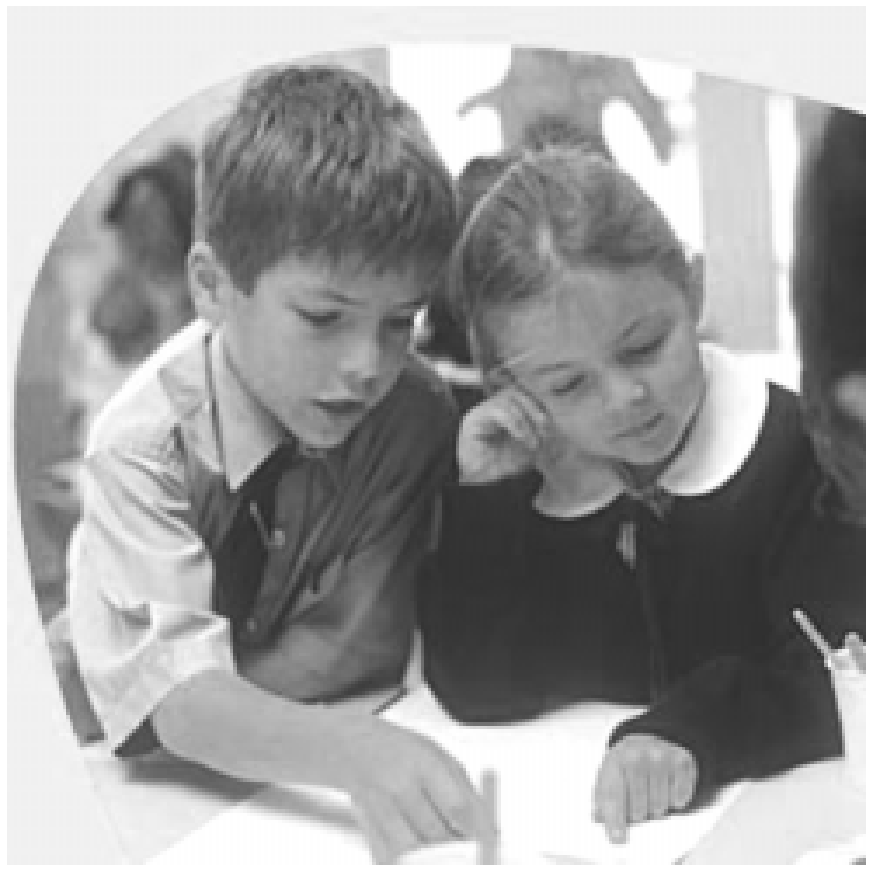

Els llibres Decideix /i Decideix //estan estructurats en vint capítols i de la mateixa manera. És molt important que abans de fer qualsevol sessió els mestres ens llegim bé la introducció i l'objectiu o objectius de la sessió. Es tracta de tenir molt present el perquè del que estem fent.

Per als mestres és fàcil d'aplicar, ja que les instruccions són molt clares; t'explica pas a pas com ho has de fer, i la majoria de material només cal fotocopiar-lo.

Els objectius del programa estan repartits segons les lliçons. A les primeres: ajudar l'alumnat a centrar l'atenció en el llenguatge i les accions i ensenyar a controlar les seves accions (autoinstruccions). Es fan activitats d'atenció visual i auditiva i de modelatge, amb les quals els i les alumnes no tenen cap relació afectiva.

Després: identificar les emocions bàsiques amb fotografies, dibuixos... I a veure que les emocions són produïdes per unes causes. A continuació: exercitar els pensaments necessaris per a la relació interpersonal: causal, alternatiu, conseqüencial i de perspectiva. I per 


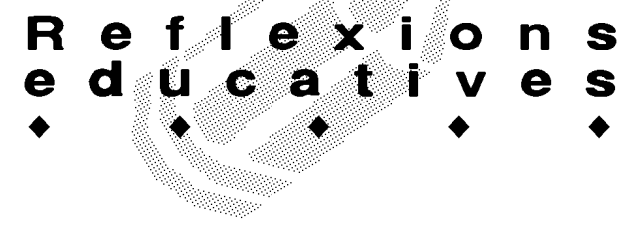

acabar, treballar els criteris per triar la millor solució a un problema interpersonal: seguretat, justícia, sentiments que produeix i eficàcia.

Totes les activitats del programa són molt atractives per a la canalla. Tot i que a vegades s'ho prenen com un joc, el més important és que en acabar l'activitat reflexionem tal com se'ns indica. Convé extrapolar a totes les situacions possibles les maneres de fer del Decideix, i sobretot les "Preguntes màgiques".

Implementar-lo a l'escola no és difícil. Com diuen el Manuel i la Margarita: "Si ho comença un mestre o una mestra, en veure els resultats, segur que d'altres s'animaran a fer-lo". La proposta que faig és que només farà falta la formació d'algunes persones de l'equip docent, el compromís del claustre, amb la seva inclusió al currículum, la creació d'una comissió (una persona per cicle, com a mínim) que en faci el seguiment, que algú que hagi rebut la formació faci de coordinador/a i l'aprovació del Consell Escolar.

És molt important, com en totes les accions educatives, comptar també amb la col·laboració de les famílies. Per això a la reunió de començament de curs se les informarà i se'ls demanarà que a partir d'ara mirin de resoldre els seus conflictes i problemes tal com ho fem al Decideix. També, junt amb el Decideix, hi ha uns materials anomenats Megahabilitats, que són les habilitats més necessàries per fer tallers amb les famílies.

Aquest programa l'apliquem a l'escola on treballo, des del curs 2000-2001 a Cicle Mitjà i a Cicle Superior. Als grups on s'ha treballat el programa se'ls nota una millora en la seva relació, amb la manera de resoldre els conflictes i fins i tot, a nivell acadèmic.

Em consta que hi ha moltes escoles on els i les mestres el fan servir. De fet, a les nostres contrades s'han fet moltes sessions de formació.

Jo he tingut la sort de conèixer personalment el Manuel Segura i la Margarita Arcas, i de rebre la formació de primera mà. Ha estat un plaer, ja que no hi ha dubte que són uns grans comunicadors i que es creuen allò que expliquen. Us encoratjo que, si podeu, els aneu a escoltar quan facin alguna conferència. Si no en teniu ocasió, als centres de Recursos tenen un vídeo d'una conferència del doctor Segura, on s'explica el programa.

Suposo que, si heu llegit fins aquí, no cal que us digui que us el recomano de tot cor. Penso que, a més d'anar bé per a la canalla, també ens ajuda a les persones que el fem. De la nostra habilitat com a educadors o educadores i, sobretot, del nostre entusiasme, dependrà que en traguem profit i que els nois i les noies obtinguin bons resultats.

\section{Referències bibliogràfiques}

SEGURA MORALES, MANUEL; EXPÓSITO, JUANA R: ARCAS CUENCA, MARGARITA; LIMA GONZÁLEZ, RUBÉN i PÉREZ DÍAZ, JOSÉ CARLOS. Decideix /i Decideix //. Edit. Departament d'Ensenyament. Barcelona. 2001.

CAMP, B.W. Verbal mediation in young aggresive boys. «Journal of abnormal child Psichology», (1977).

GARDNER, HOWARD. La nueva ciencia de la mente. Edit. Paidós. Barcelona. 1988.

GARDNER, HOWARD. Inteligencias múltiples. Edit. Paidós. Barcelona. 1995.

LURIA, A. The role of speechin the regulations of normal and abnormal behavior. Edit. Liveright. New York. 1961.

VYGOTSKY, L. Thought and language. Edit. Wiley. Nova York. 1962.

WHITE, S. H. Some general outlines of the matrix of develop-mental changes between five and seven years. «Bulletin of the Orton Society», (1970).

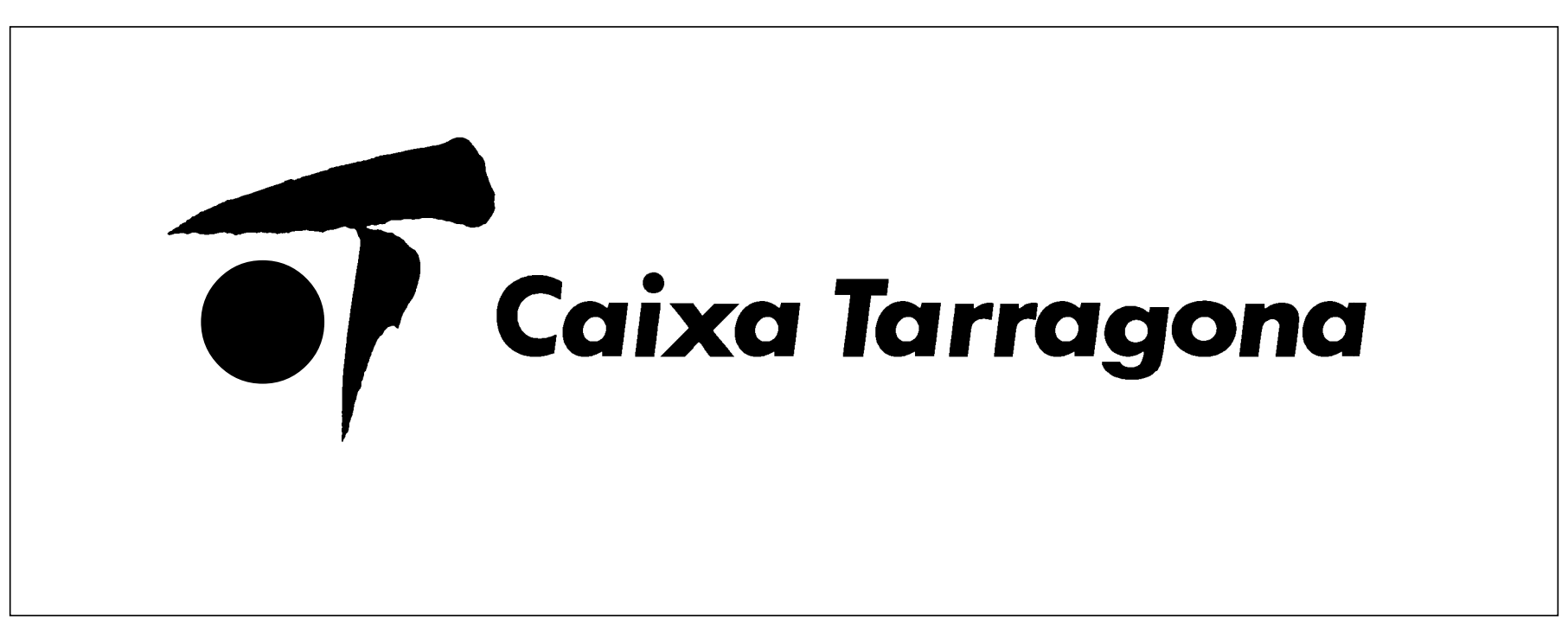

